\title{
Exclusionary Conduct of Dominant Firms, R\&D Competition, and Innovation
}

\author{
Jonathan B. Baker ${ }^{1}$
}

Published online: 11 September 2015

(C) The Author(s) 2015. This article is published with open access at Springerlink.com

\begin{abstract}
This article evaluates the innovation consequences of antitrust enforcement against the exclusionary conduct of dominant firms through a Nash equilibrium model of research and development (R\&D) competition to create new products. In the two-firm model, whether one firm regards the other's R\&D investment as a strategic complement or substitute turns on an increasing differences condition: whether the first firm's incremental benefit of increased R\&D investment is greater if its rival's R\&D effort succeeds or fails. Antitrust prohibitions on pre-innovation product market exclusion, post-innovation product market exclusion, and exclusion from R\&D competition, are found to be effective in different strategic settings.
\end{abstract}

Keywords Antitrust - Dominant firms · Exclusion - Innovation $\cdot$ R\&D

\section{Introduction}

The antitrust concern with monopolization is not limited to prices; it also includes a dominant firm's suppression of new technologies, products, and business models. Two well-known monopolization cases provide illustrations. At the start of the twenty-first century, Microsoft, which was the monopolist of operating systems for Intel-compatible personal computers, was found to have prevented nascent operating system competition by excluding Netscape's browser and Sun's Java programming language. A half century before, the Lorain Journal newspaper

Jonathan B. Baker

jbaker@wcl.american.edu

1 American University Washington College of Law, 4801 Massachusetts Ave., NW,

Washington, DC 20016, USA 
protected its monopoly on advertising by local businesses by excluding a radio station entrant. ${ }^{1}$

This article evaluates the innovation consequences of antitrust enforcement against exclusionary conduct by a dominant firm through a Nash equilibrium model of research and development (R\&D) competition between a dominant firm and a rival to create new products. ${ }^{2}$ The article is concerned solely with incentives to innovate; it abstracts from the potential benefits of antitrust enforcement in lowering (quality-adjusted) prices and increasing output in static markets. In the model, R\&D investment increases the prospects of innovation success but does not influence post-investment price competition in the event that both firms succeed. ${ }^{3}$ These simplifications make transparent the role of strategic interactions that involve R\&D investment.

In particular, the model demonstrates that enforcement actions that challenge preinnovation exclusion and enforcement actions that challenge post-innovation exclusion will tend to be effective in different strategic settings. ${ }^{4}$ An antitrust prohibition on dominant firm exclusion of its rival from post-innovation (preinnovation) product market competition will tend to increase the overall likelihood of industry innovation if the dominant firm's best response function slopes upward (downward) and is sufficiently steep, or if its rival's best response function slopes downward (upward) and is sufficiently steep. In addition, an antitrust prohibition on dominant firm exclusion of its rival from $R \& D$ competition increases the overall likelihood of industry innovation if the dominant firm regards its rival's R\&D investment as a strategic complement (its best response function slopes upward).

The model also shows that whether one firm regards the other firm's R\&D investment as a strategic complement or strategic substitute turns on an increasing differences condition: whether the first firm's incremental benefit of increased R\&D investment is greater if its rival's R\&D effort succeeds or if its rival's R\&D effort fails. ${ }^{5}$ Baker (2016) applies these results to identify observable factors that would suggest whether dominant firms are likely to regard rival R\&D as a strategic

\footnotetext{
${ }^{1}$ Baker (2013) discusses these cases and the antitrust treatment of exclusionary conduct generally.

${ }^{2}$ For recent surveys of the extensive economic literature relating competition and innovation, see Gomellini (2013), Shapiro (2012), Schmutzler (2010), Baker (2007), and Gilbert (2006).

3 Aoki and Spiegel (2010) specify a model with the same mathematical structure to study the innovation consequences of pre-grant patent publication.

${ }^{4}$ Pre-innovation product market exclusion by a dominant firm may involve conduct that raises its rival's costs (input foreclosure) or inhibits its rival's access to the market (customer foreclosure). A dominant firm can also impede post-innovation product market competition by its rival in the event that both firms innovate, as through technological investments in product incompatibility; loyalty discounts; tying; locking-in customers through the sale of complementary products; investments that raise buyer switching or search costs; or the creation of impediments to a rival's challenges to a firm's misuse of intellectual property.

5 Other models of R\&D competition also identify conditions under which a dominant firm treats rival R\&D investment as a strategic complement. For example, in a two-stage game with R\&D investment in cost reduction followed by Cournot competition, R\&D efforts are strategic complements if the degree of spillovers is sufficiently large (Vives (2008), p. 455, n. 40). R\&D efforts are also strategic complements in patent race models where the game is log-supermodular (Vives, 2005), p. 454). On the other hand, Schmutzler (2010, p. 386; 2013, pp. 482, 483) suggests that when innovation is cost-reducing, R\&D investments are likely strategic substitutes for both firms in a duopoly, absent spillovers.
} 
complement or strategic substitute and to evaluate whether antitrust enforcers and courts should question a dominant firm's claim that alleged exclusionary conduct enhances its incentive to innovate by increasing its return to $R \& D$ investment.

\section{Model}

\subsection{Setup}

In the model, two firms that sell differentiated products - a dominant firm and its rival-compete to develop new or upgraded (next-generation) products by investing in $R \& D$. Strategic interaction is limited to $R \& D$. $R \& D$ investments need not succeed, but greater R\&D investments make innovation success more likely. The dominant firm may employ exclusionary practices that limit pre-innovation competition or create impediments to post-innovation competition, but the rival may not do so. ${ }^{6}$

The model implicitly presumes that the firms make decisions during two periods, but their interaction reduces to a one-stage game. In the first period, both firms invest in R\&D that is aimed at developing a new or next-generation product. Each firm's investment affects its likelihood of successful innovation, which in turn affects its profits. There are no spillovers from one firm's R\&D to its rival.

In the second period, uncertainty about each firm's innovation success is resolved and the firms receive payoffs. Payoffs do not vary directly with the level of investment but do vary with whether innovation occurs (which is affected by investment). Under this simplifying assumption, discussed more in Sect. 3.1, each firm has only one possible way to innovate.

The dominant firm is designated firm 1; its rival is designated firm 2. Each firm chooses $R \& D$ investment level $\mathrm{I}^{\mathrm{i}}$, for $\mathrm{i}=1$, 2. Its costs of $\mathrm{R} \& \mathrm{D}$ investment are $\mathrm{C}^{\mathrm{i}}=\mathrm{C}\left(\mathrm{I}^{\mathrm{i}}\right)$, with $\mathrm{C}_{\mathrm{i}}^{\mathrm{i}}>0$ and $\mathrm{C}_{\mathrm{ii}}^{\mathrm{i}}>0$. (The subscript $i$ indicates differentiation with respect to $\mathrm{I}^{\mathrm{i}}$.) Any costs of impeding competition through exclusionary conduct are included in $\mathrm{C}^{1}$ and do not vary with $\mathrm{I}^{1}$.

Each firm's probability of successfully innovating depends solely on the level of its R\&D investment: $\mathrm{q}^{\mathrm{i}}=\mathrm{q}^{\mathrm{i}}\left(\mathrm{I}^{\mathrm{i}}\right)$. By assumption $0<\mathrm{q}^{\mathrm{i}}<1, \mathrm{q}_{\mathrm{i}}^{\mathrm{i}}>0$, and $\mathrm{q}_{\mathrm{ii}}^{\mathrm{i}}<0$, for $\mathrm{i}=1,2$. One concern of the Schumpeterian growth literature-the possibility that a firm's likelihood of successful innovation depends on the extent to which its current technology lags that of its rival-could lie behind differences between the functions $\mathrm{q}^{1}\left(\mathrm{I}^{1}\right)$ and $\mathrm{q}^{2}\left(\mathrm{I}^{2}\right)$, but those relationships are not modeled.

The second period is characterized by four possible states of the world: Both firms may succeed in innovating; neither may succeed in doing so; only the dominant firm may succeed; or only the rival may succeed. The payoffs to the firms may be interpreted as the discounted present value of a future profit stream, and the terms profit and payoff are used interchangeably.

\footnotetext{
${ }^{6}$ In the model, the dominant firm and its rival also differ in two other ways: Exclusionary impediments to product market competition increase dominant firm profits but reduce rival profits; and the dominant firm receives a higher payoff than its rival when neither firm's $R \& D$ investment succeeds.
} 
The payoffs in each state of the world and the ex ante probabilities of achieving each are summarized in Tables 1 and $2 . \Pi^{\mathrm{ijk}}$ represents payoffs to firm $i$ in state of the world $(\mathrm{j}, \mathrm{k})$, where $j$ indicates whether the dominant firm succeeded ( $\mathrm{s}$ ) or failed (f) in its innovation efforts and $k$ similarly indicates whether the rival succeeded or failed. All payoffs are non-negative.

Payoffs when both firms innovate (the (s, s) state of the world) depend on exclusionary impediments to post-innovation competition $\delta$. This parameter increases as exclusionary impediments are removed. A lessening of exclusionary impediments to post-innovation competition reduces dominant firm profits $\left(\Pi_{\delta}^{1 \mathrm{ss}}(\delta)<0\right.$, for all $\left.\delta\right)$ and increases rival profits $\left(\Pi_{\delta}^{2 \mathrm{ss}}(\delta)>0\right.$, for all $\left.\delta\right)$. These assumptions rule out strategies in which the dominant firm discourages rival investment in R\&D by committing to aggressive post-innovation competition. ${ }^{7}$

When neither firm innovates [the (f, f) state of the world], the firms compete in price with existing products. Payoffs depend on exclusionary impediments to preinnovation product market competition $\theta$, which increases as impediments are removed. By assumption, a reduction in exclusionary impediments to preinnovation competition lessens dominant firm profits $\left(\Pi_{\theta}^{1 \mathrm{ff}}(\theta)<0\right.$, for all $\left.\theta\right)$, increases rival profits $\left(\Pi_{\theta}^{2 \mathrm{ff}}(\theta)>0\right.$, for all $\left.\theta\right)$, and lowers aggregate industry profits $\left(\Pi_{\theta}^{1 \mathrm{ff}}(\theta)+\Pi_{\theta}^{2 \mathrm{ff}}(\theta)<0\right.$, for all $\left.\theta\right)$. In addition, pre-innovation profits are greater for the dominant firm $\left(\Pi^{1 \mathrm{ff}}(\theta)>\Pi^{2 \mathrm{ff}}(\theta)\right.$, for all $\left.\theta\right)$. These assumptions build in an Arrow replacement effect, by which the dominant firm has a greater opportunity cost of innovation than the rival because innovation cannibalizes the dominant firm's greater pre-innovation profits.

Each firm is assumed to profit (individually) from innovation. Hence, $\Pi^{1 \mathrm{ss}}(\delta)>\Pi^{1 \mathrm{fs}}$ and $\Pi^{2 \mathrm{ss}}(\delta)>\Pi^{2 \mathrm{sf}}$ for all $\delta ; \Pi^{1 \mathrm{sf}}>\Pi^{1 \mathrm{ff}}(\theta)$ and $\Pi^{2 \mathrm{fs}}>\Pi^{2 \mathrm{ff}}(\theta)$ for all $\theta ; \Pi^{1 \mathrm{sf}}>\Pi^{1 \mathrm{fs}}$ and $\Pi^{2 \mathrm{fs}}>\Pi^{2 \mathrm{sf}} ;$ and $\Pi^{1 \mathrm{ss}}(\delta)>\Pi^{1 \mathrm{ff}}(\theta)$ and $\Pi^{2 \mathrm{ss}}(\delta)>\Pi^{2 \mathrm{ff}}(\theta)$ for all $\delta$ and $\theta$.

The assumption that innovation is profitable for each firm individually implies that aggregate profits are greater when both firms innovate than when neither succeeds in doing so $\left(\Pi^{1 \mathrm{ss}}(\delta)+\Pi^{2 \mathrm{ss}}(\delta)>\Pi^{2 \mathrm{ff}}(\theta)+\Pi^{1 \mathrm{ff}}(\theta)\right.$ for all $\delta$ and $\left.\theta\right)$. When both firms succeed, moreover, competition is assumed to reduce aggregate profits relative to the outcome in which only one firm succeeds in innovating, so $\left(\Pi^{1 \mathrm{sf}}+\Pi^{2 \mathrm{sf}}\right)>\left(\Pi^{1 \mathrm{ss}}(\delta)+\Pi^{2 \mathrm{ss}}(\delta)\right)>0$, and $\left(\Pi^{1 \mathrm{fs}}+\Pi^{2 \mathrm{fs}}\right)>\left(\Pi^{1 \mathrm{ss}}(\delta)+\Pi^{2 \mathrm{ss}}\right.$ $(\delta))>0$, for all $\delta .{ }^{8}$ Aggregate industry profits are also assumed to be greater if either firm successfully innovates than if neither does so, so $\left(\Pi^{1 \mathrm{sf}}+\Pi^{2 \mathrm{sf}}\right)>$ $\left(\Pi^{1 \mathrm{ff}}(\theta)+\Pi^{2 \mathrm{ff}}(\theta)\right)>0$ and $\left(\Pi^{1 \mathrm{fs}}+\Pi^{2 \mathrm{fs}}\right)>\Pi^{1 \mathrm{ff}}(\theta)+\Pi^{2 \mathrm{ff}}(\theta)>0$, for all $\theta$.

\footnotetext{
7 When a dominant firm can employ exclusionary strategies, the removal of exclusionary impediments enhances product market competition by improving the ability of rivals to contest the market, which increases the rival's rewards. By contrast, the Schumpeterian growth literature models increased product market competition as arising from greater imitation, which reduces the rival's rewards. (Shapiro, 2012, pp. 372-374). The Schumpeterian literature also addresses two issues not explicitly treated here: the influence of the discrepancy between the technology of a laggard and the leader on each firm's incentives to invest in R\&D (Aghion et al. (2014); Athey and Schmutzler (2011)), and the potential erosion of the distinction between policies that foster pre-innovation competition and policies that foster post-innovation competition when firms engage in successive rounds of innovation (Segal and Whinston 2007).

${ }^{8}$ This assumption restricts the extent to which post-innovation product differentiation expands the overall market.
} 
Table 1 Payoffs in each state of the world

\begin{tabular}{lll}
\hline Firm 1, Firm 2) & Firm 2 succeeds & Firm 2 does not succeed \\
\hline Firm 1 succeeds & $\Pi^{1 \mathrm{ss}}(\delta), \Pi^{2 \mathrm{ss}}(\delta)$ & $\Pi^{1 \mathrm{sf}}, \Pi^{2 \mathrm{sf}}$ \\
Firm 1 does not succeed & $\Pi^{1 \mathrm{fs}}, \Pi^{2 \mathrm{fs}}$ & $\Pi^{1 \mathrm{ff}}(\theta), \Pi^{2 \mathrm{ff}}(\theta)$ \\
\hline
\end{tabular}

Table 2 Probability that each state of the world arises

\begin{tabular}{lll}
\hline & Firm 2 succeeds & Firm 2 does not succeed \\
\hline Firm 1 succeeds & $\mathrm{q}^{1} \mathrm{q}^{2}$ & $\mathrm{q}^{1}\left(1-\mathrm{q}^{2}\right)$ \\
Firm 1 does not succeed & $\left(1-\mathrm{q}^{1}\right) \mathrm{q}^{2}$ & $\left(1-\mathrm{q}^{1}\right)\left(1-\mathrm{q}^{2}\right)$ \\
\hline
\end{tabular}

The assumptions with regard to the effects of $\delta$ and $\theta$ on payoffs collectively define a competition policy intervention against exclusionary conduct broadly: any public policy that reduces dominant firm payoffs and increases rival payoffs in the pertinent state of the world (pre- or post-innovation) in which both compete with same-generation products. ${ }^{9}$ When exclusionary conduct would affect both preinnovation and post-innovation competition, the same policy may be regarded as simultaneously affecting $\delta$ and $\theta$. The model's simple temporal structure avoids analytical complications that are associated with sequential innovation, in which the future product market competition that follows one round of product improvements would also represent the pre-innovation product market competition that precedes the next round.

The payoffs allow each firm's R\&D investment decision to reflect a mixture of two motives. One is the incentive to escape competition. Investment in R\&D frees each firm from competition with a finite probability: If a firm succeeds in innovating, it will avoid the state of the world in which neither firm succeeds (in which the firms compete on price using existing products), and it has a chance of avoiding the state of the world in which both firms succeed (in which the firms compete on price with new products).

In addition, firm investment decisions reflect an incentive to innovate in order to capture profits that arise from the increase in demand that is associated with bringing a new or next-generation product to market. The expected payoff for successful innovation is a probability-weighted sum of the profit in the event that the rival firm does not also succeed and the smaller profit in the event that both firms succeed.

\footnotetext{
${ }^{9}$ By assumption, exclusionary conduct does not affect either firm's profits in states of the world in which one firm innovates while the other does not.
} 


\subsection{Optimization and Equilibrium}

During the first period, the two firms simultaneously choose investment levels to maximize $\mathrm{V}^{1}$ and $\mathrm{V}^{2}$, the expected value of the dominant firm and rival respectively, where

$$
\begin{aligned}
\mathrm{V}^{1}= & \mathrm{q}^{1}\left(\mathrm{I}^{1}\right)\left(1-\mathrm{q}^{2}\left(\mathrm{I}^{2}\right)\right) \Pi^{1 \mathrm{sf}}+\mathrm{q}^{1}\left(\mathrm{I}^{1}\right) \mathrm{q}^{2}\left(\mathrm{I}^{2}\right) \Pi^{1 \mathrm{ss}}(\delta) \\
& +\left(1-\mathrm{q}^{1}\left(\mathrm{I}^{1}\right)\right)\left(1-\mathrm{q}^{2}\left(\mathrm{I}^{2}\right)\right) \Pi^{1 \mathrm{ff}}(\theta)+\left(1-\mathrm{q}^{1}(\mathrm{I})\right) \mathrm{q}^{2}\left(\mathrm{I}^{2}\right) \Pi^{1 \mathrm{fs}}-\mathrm{C}^{1}\left(\mathrm{I}^{1}\right)
\end{aligned}
$$

and

$$
\begin{aligned}
\mathrm{V}^{2}= & \mathrm{q}^{2}\left(\mathrm{I}^{2}\right)\left(1-\mathrm{q}^{1}\left(\mathrm{I}^{1}\right)\right) \Pi^{2 \mathrm{fs}}+\mathrm{q}^{2}\left(\mathrm{I}^{2}\right) \mathrm{q}^{1}\left(\mathrm{I}^{1}\right) \Pi^{2 \mathrm{ss}}(\delta) \\
& +\left(1-\mathrm{q}^{2}\left(\mathrm{I}^{2}\right)\right)\left(1-\mathrm{q}^{1}\left(\mathrm{I}^{1}\right)\right) \Pi^{2 \mathrm{ff}}(\theta)+\left(1-\mathrm{q}^{2}\left(\mathrm{I}^{2}\right)\right) \mathrm{q}^{1}\left(\mathrm{I}^{1}\right) \Pi^{2 \mathrm{sf}}-\mathrm{C}^{2}\left(\mathrm{I}^{2}\right) .
\end{aligned}
$$

The equilibrium values of $\mathrm{I}^{1}$ and $\mathrm{I}^{2}$ are determined by the simultaneous solution of the two first order conditions

$$
\mathrm{V}_{1}^{1}=0=\mathrm{q}_{1}^{1}\left(1-\mathrm{q}^{2}\right) \Pi^{1 \mathrm{sf}}+\mathrm{q}_{1}^{1} \mathrm{q}^{2} \Pi^{1 \mathrm{ss}}-\mathrm{q}_{1}^{1}\left(1-\mathrm{q}^{2}\right) \Pi^{1 \mathrm{ff}}-\mathrm{q}_{1}^{1} \mathrm{q}^{2} \Pi^{1 \mathrm{fs}}-\mathrm{C}_{1}^{1}
$$

and

$$
\mathrm{V}_{2}^{2}=0=\mathrm{q}_{2}^{2}\left(1-\mathrm{q}^{1}\right) \Pi^{2 \mathrm{fs}}+\mathrm{q}_{2}^{2} \mathrm{q}^{1} \Pi^{2 \mathrm{ss}}-\mathrm{q}_{2}^{2}\left(1-\mathrm{q}^{1}\right) \Pi^{2 \mathrm{ff}}-\mathrm{q}_{2}^{2} \mathrm{q}^{1} \Pi^{2 \mathrm{sf}}-\mathrm{C}_{2}^{2} .
$$

Second order conditions for a maximum $\left(\mathrm{V}_{11}^{1}<0\right.$ and $\left.\mathrm{V}_{22}^{2}<0\right)$ are assumed to be satisfied. Equilibrium investments are conditional on the extent of the exclusionary impediments that are indexed by $\theta$ and $\delta$; so these investments can be written $\mathrm{I}^{\mathrm{i}}(\theta$, $\delta)$. The analysis in the remainder of Sect. 2 will consider these impediments one at a time, so it will be convenient to write $\mathrm{I}^{\mathrm{i}}(\mathrm{z})$, where $\mathrm{z}$ represents $\theta$ or $\delta$, as appropriate. (A third policy instrument-greater innovation competition from challenging practices that raise rival R\&D costs - is addressed below in Sect. 3.2.)

The policymaker considers a competition policy intervention that alters $\mathrm{z}$ based on whether the intervention increases the probability $p$ that at least one firm succeeds, where $\mathrm{p}(\mathrm{z})=\mathrm{q}^{1}+\mathrm{q}^{2}-\mathrm{q}^{1} \mathrm{q}^{2} \cdot{ }^{10}$ The policymaker does not care which firm innovates. The policymaker does not seek to identify the optimal policy intervention; instead it evaluates the consequences of a small change in $\mathrm{z}$ for the likelihood of industry innovation.

By differentiating the definition of $\mathrm{p}(\mathrm{z})$, it is evident that a competition policy intervention that raises $\mathrm{z}$ by a small amount will increase $\mathrm{p}$ if and only if $\mathrm{dp} / \mathrm{dz}=\mathrm{q}_{1}^{1}\left(1-\mathrm{q}^{2}\right) \mathrm{dI}^{1} / \mathrm{dz}+\mathrm{q}_{2}^{2}\left(1-\mathrm{q}^{1}\right) \mathrm{dI}^{2} / \mathrm{dz}>0$. This equation formalizes the intuitive idea that a policy intervention may benefit innovation if it leads to a substantial increase in one firm's incentives to invest and its resulting likelihood of success, without markedly reducing the other firm's incentives to invest.

\footnotetext{
${ }^{10}$ In practice, the antitrust enforcement agencies would be expected to prefer that multiple firms succeed when industry features like intellectual property rights or network effects do not make innovation competition winner-take-all. It is reasonable to assume that agency preferences are lexicographic, however, in recognition of the many studies that find that the social return to innovation substantially exceeds the private return and that identify substantial social gains to new product introductions in individual industries.
} 
Each firm is assumed to be able to make an informed judgment about the way that its rival's investment level depends on the policy variables $\theta$ and $\delta$, and to account for rival responses in choosing investment levels and responding to competition policy interventions. The latter responses will depend on the partial derivatives of the first-order conditions, which are set forth in Table 3 . The table indicates the signs of those derivatives, to the extent that they are determined by prior assumptions.

In the table, the expressions for the cross-partial derivatives $V_{12}^{1}$ and $V_{21}^{2}$ are simplified by defining two new variables $-\Delta$ and $\Psi$ - that are related to the relative size of the payoffs in various states of the world:

$$
\Delta=\left(\Pi^{1 \mathrm{ss}}-\Pi^{1 \mathrm{fs}}\right)-\left(\Pi^{1 \mathrm{sf}}-\Pi^{1 \mathrm{ff}}\right) ;
$$

and

$$
\Psi=\left(\Pi^{2 \mathrm{ss}}-\Pi^{2 \mathrm{sf}}\right)-\left(\Pi^{2 \mathrm{fs}}-\Pi^{2 \mathrm{ff}}\right) .
$$

To interpret $\Delta$, note that $\left(\Pi^{1 \mathrm{ss}}-\Pi^{1 \mathrm{fs}}\right)$ is the incremental benefit of innovation success to firm 1 , conditional on firm 2's succeeding, while $\left(\Pi^{1 \mathrm{sf}}-\Pi^{1 \mathrm{ff}}\right)$ is the incremental benefit of innovation success to firm 1, conditional on firm 2's not succeeding. Hence $\Delta$ is positive if and only if firm 1 gains more from innovation success conditional on firm 2's succeeding than it gains conditional on firm 2's not succeeding. Similarly, $\Psi$ is positive if and only if firm 2 gains more from its innovation success in the event that firm 1 also succeeds than it gains in the event that firm 1 does not succeed.

The first-order conditions (1) and (2) imply best response functions (reaction functions) for the two firms: $\mathrm{I}^{1}=\rho_{1}\left(\mathrm{I}^{2}\right)$ for the dominant firm; and $\mathrm{I}^{2}=\rho_{2}\left(\mathrm{I}^{1}\right)$ for its rival. These functions are assumed invertible, which allows the dominant firm's reaction function to be written $\mathrm{I}^{2}=\rho_{1}^{-1}\left(\mathrm{I}^{1}\right)$. Reaction function slopes are defined by differentiating functions of the form $\mathrm{I}^{2}\left(\mathrm{I}^{1}\right)$ with respect to $\mathrm{I}^{1}$ :

$$
\mathrm{R}^{1}=\mathrm{d} \rho_{1}^{-1} / \mathrm{dI}^{1}=-\mathrm{V}_{11}^{1} / \mathrm{V}_{12}^{1}=-\mathrm{V}_{11}^{1} /\left(\mathrm{q}_{1}^{1} \mathrm{q}_{2}^{2} \Delta\right) ;
$$

and

$$
\mathrm{R}^{2}=\mathrm{d} \rho_{2} / \mathrm{dI}{ }^{1}=-\mathrm{V}_{21}^{2} / \mathrm{V}_{22}^{2}=-\left(\mathrm{q}_{1}^{1} \mathrm{q}_{2}^{2} \Psi\right) / \mathrm{V}_{22}^{2}
$$

The signs of the reaction function slopes are the same as the signs of $\Delta$ and $\Psi$, respectively. If $\Delta$ and $\Psi$ are both positive, each best response function is upward sloping (strategic complements); if $\Delta$ and $\Psi$ are both negative, each best response function is downward sloping (strategic substitutes). If $\Delta$ and $\Psi$ take on opposite signs, the best response functions differ in the sign of their slopes.

Equation (3) implies that the dominant firm regards its rival's R\&D investment as a strategic substitute (firm 1's reaction function slopes downward), if and only if firm 1's incremental gains from innovating are greater when firm 2 does not succeed. Intuitively, a less aggressive $R \& D$ investment strategy by firm 2-a reduction in the second firm's R\&D investment-lessens that firm's likelihood of innovation success. If the incremental benefit of $R \& D$ investment by firm 1 
Table 3 Partial derivatives of the first-order conditions

\begin{tabular}{lll}
\hline & & Sign \\
\hline $\mathrm{V}_{11}^{1}$ & $\mathrm{q}_{11}^{1}\left(1-\mathrm{q}^{2}\right) \Pi^{1 \mathrm{sf}}+\mathrm{q}_{11}^{1} \mathrm{q}^{2} \Pi^{1 \mathrm{ss}}-\mathrm{q}_{11}^{1}\left(1-\mathrm{q}^{2}\right) \Pi^{1 \mathrm{ff}}-\mathrm{q}_{11}^{1} \mathrm{q}^{2} \Pi^{1 \mathrm{fs}}-\mathrm{C}_{11}^{1}$ & $<0$ \\
$\mathrm{~V}_{22}^{2}$ & $\mathrm{q}_{2}^{22}\left(1-\mathrm{q}^{1}\right) \Pi^{2 \mathrm{fs}}+\mathrm{q}_{2}^{22} \mathrm{q}^{1} \Pi^{2 \mathrm{ss}}-\mathrm{q}_{2}^{22}\left(1-\mathrm{q}^{1}\right) \Pi^{2 \mathrm{ff}}-\mathrm{q}_{2}^{22} \mathrm{q}^{1} \Pi^{2 \mathrm{sf}}-\mathrm{C}_{22}^{2}$ & $<0$ \\
$\mathrm{~V}_{12}^{1}$ & $\mathrm{q}_{1}^{1} \mathrm{q}_{2}^{2}\left[\left(\Pi^{1 \mathrm{ss}}-\Pi^{1 \mathrm{fs}}\right)-\left(\Pi^{1 \mathrm{sf}}-\Pi^{1 \mathrm{ff}}\right)\right]=\mathrm{q}_{1}^{1} \mathrm{q}_{2}^{2} \Delta$ & Sign $(\Delta)$ \\
$\mathrm{V}_{21}^{2}$ & $\mathrm{q}_{1}^{1} \mathrm{q}_{2}^{2}\left[\left(\Pi^{2 \mathrm{ss}}-\Pi^{2 \mathrm{sf}}\right)-\left(\Pi^{2 \mathrm{fs}}-\Pi^{2 \mathrm{ff}}\right)\right]=\mathrm{q}_{1}^{1} \mathrm{q}_{2}^{2} \Psi$ & Sign $(\Psi)$ \\
$\mathrm{V}_{1 \delta}^{1}$ & $\mathrm{q}_{1}^{1} \mathrm{q}^{2} \Pi_{\delta}^{1 \mathrm{ss}}$ & $<0$ \\
$\mathrm{~V}_{2 \delta}^{2}$ & $\mathrm{q}^{1} \mathrm{q}_{2}^{2} \Pi_{\delta}^{2 \mathrm{ss}}$ & $>0$ \\
$\mathrm{~V}_{1 \theta}^{1}$ & $-\mathrm{q}_{1}^{1}\left(1-\mathrm{q}^{2}\right) \Pi_{\theta}^{1 \mathrm{fff}}$ & $>0$ \\
$\mathrm{~V}_{2 \theta}^{2}$ & $-\left(1-\mathrm{q}^{1}\right) \mathrm{q}_{2}^{2} \Pi_{\theta}^{2 \mathrm{ff}}$ & $<0$ \\
\hline
\end{tabular}

increases as a result - if $\Delta$ is negative - then the first firm will have an incentive to invest more in $\mathrm{R} \& \mathrm{D}$. Accordingly, when $\Delta$ is negative, firm 1 regards its rival's investment as a strategic substitute. Moreover, $\Delta$ is positive if and only if firm 1 regards its rival's investment as a strategic complement.

Equation (4) similarly implies that $\Psi$ is negative if and only if firm 2 regards the dominant firm's R\&D investment as a strategic substitute, and $\Psi$ is positive if and only if firm 2 regards the dominant firm's R\&D investment as a strategic complement. Increasing differences conditions appear because the R\&D game is supermodular when $\mathrm{V}_{11}^{1} \geq 0$ and $\mathrm{V}_{21}^{2} \geq 0$.

Reaction functions can slope in different directions, as $\Delta$ and $\Psi$ need not have the same sign. For example, two market features - a high market share for the dominant firm in the event that both firms innovate, and a high likelihood that its rival would take a substantial fraction of customers away from the dominant firm in the event that only the rival innovates - tend to increase $\Delta$ while reducing $\Psi$, possibly leading the dominant firm to regard its rival's $R \& D$ investment as a strategic complement $(\Delta>0)$, while the rival simultaneously views dominant firm investment as a strategic substitute $(\Psi<0) .^{11}$

\subsection{Stability}

The conditions for stability of the model's Nash equilibria vary depending on whether the reaction functions slope in the same or opposite directions. Local stability of the Nash equilibrium of this two-player game with one-dimensional

\footnotetext{
${ }^{11}$ Baker (2016) provides examples of R\&D competition that involved IBM, Microsoft, and Xerox where dominant firm and rival reaction functions may have had different slopes, and Tombak (2006) suggests the same for Boeing and Airbus's investment decisions. In addition, suppose that an industry is characterized by what Athey and Schmutzler (2011) term "weak increasing dominance" (a firm with low marginal cost invests more than its rival), and the dominant firm is a technological leader. If the technological leader's conduct is dominated by a desire to extend its lead (because higher R\&D increases the marginal benefit of investment net of cost) while the laggard's conduct is dominated by a desire not to take on the leader (because it obtains little marginal benefit from R\&D investment and has a high marginal cost), then the dominant firm's reaction function would likely be upward sloping and its rival's reaction function would likely be downward sloping.
} 
strategy spaces requires that $\left|R^{2}\right| /\left|R^{1}\right|<1$, or equivalently, that $\left|R^{1}\right|>\left|R^{2}\right|$. (See Vives, 1999, p. 51.) If $R^{1}$ and $R^{2}$ have the same sign, the Nash equilibrium is stable if and only if $\mathrm{D}=\mathrm{V}_{11}^{1} \mathrm{~V}_{22}^{2}-\mathrm{V}_{12}^{1} \mathrm{~V}_{21}^{2}>0$, where $D$ is the determinant of the matrix of own- and cross-partial derivatives of the first-order condition. If $\mathrm{R}^{1}$ and $\mathrm{R}^{2}$ have opposite signs, the Nash equilibrium is stable if and only if $\mathrm{V}_{11}^{1} \mathrm{~V}_{22}^{2}+\mathrm{V}_{12}^{1} \mathrm{~V}_{21}^{2}>0$

Each stability condition requires that firm 1 have the steeper reaction function. D $>0$ assures stability when reaction functions slope in the same direction. If reaction functions slope in opposite directions, $\mathrm{D}>0$ necessarily holds, but $\mathrm{D}>0$ is no longer sufficient for stability. To guarantee stability in that case, it is sufficient to assume that when reaction functions have different signs, decreasing returns to scale in dominant firm investments in $R \& D$ are sufficiently strong $\left(C_{11}^{1}\right.$ is sufficiently large) as to make $\mathrm{V}_{11}^{1}$ sufficiently large in absolute value to assure that $\mathrm{V}_{11}^{1} \mathrm{~V}_{22}^{2}>-\left(\mathrm{q}_{1}^{1} \mathrm{q}_{2}^{2}\right)^{2} \Delta \Psi>0 .^{12}$

\subsection{Consequences of Policy Interventions for R\&D Investment and the Likelihood of Innovation}

The policy interventions are analyzed using a comparative statics approach, which presumes that those interventions are small. This assumption excludes interventions that would alter payoffs so substantially as to change the sign of $\Delta$ or $\Psi$, and thus change the sign of a reaction function. Propositions 1 and 2 show how increases in the policy variable $z$ shift the two firms' reaction functions in a space in which $\mathrm{I}^{1}$ is on the horizontal axis. The policy variable will be interpreted in turn as a reduction in impediments to pre-innovation competition (higher $\theta$ ) and a reduction in impediments to post-innovation competition (higher $\delta$ ). Proposition 3 provides a general comparative statics result for shifts in $z$. Proofs of all propositions in this article are provided in an "Appendix".

Proposition 1 (Direction of the Shift of the Dominant Firm's Reaction Function) An increase in $z$ shifts $\rho_{1}$ [the reaction function of $I^{1}$ with respect to $\left.I^{2}\right]$ in the direction of higher $I^{1}$ if and only if $-V_{1 z}^{1} / V_{11}^{1}>0$.

Corollary For $\rho_{1}, d I^{1} / d z>0$ if and only if $V_{1 z}^{1}>0$.

Proposition 2 (Direction of the Shift of the Rival's Reaction Function) An increase in $z$ shifts $\rho_{2}$ [the reaction function of $I^{2}$ with respect to $I^{1}$ ] in the direction of higher $I^{2}$ if and only if $-V_{2 z}^{2} / V_{22}^{2}>0$.

Corollary $\operatorname{For} \rho_{2}, d I^{2} / d z>0$ if and only if $V_{2 z}^{2}>0$.

Propositions 1 and 2 imply that when the policy intervention reduces exclusionary impediments to pre-innovation competition (greater $\theta$ ), the dominant firm's reaction function shifts in the direction of greater $\mathrm{I}^{1}\left(\right.$ as $\left.\mathrm{V}_{1 \theta}^{1}>0\right)$, reflecting that firm's increased incentive to escape pre-innovation competition. The rival's

\footnotetext{
${ }^{12}$ If the stability condition for reaction functions that slope in opposite directions binds, however, it could limit the absolute values of $\Delta$ and $\Psi$ that would satisfy the condition for a policy intervention to increase the probability of innovation.
} 
reaction function shifts in the direction of lower $\mathrm{I}^{2}$ (as $\mathrm{V}_{2 \theta}^{2}<0$ ), reflecting its reduced incentive to escape pre-innovation competition.

If the policy intervention instead involves a reduction in exclusionary impediments to post-innovation competition (greater $\delta$ ), each reaction function shifts in a direction that is opposite to the way that it shifts in response to a reduction in exclusionary impediments to pre-innovation competition. With $\mathrm{V}_{1 \delta}^{1}<0$, the dominant firm's reaction function shifts in the direction of lower $\mathrm{I}^{1}$, which reflects that firm's lessened incentive to invest in $R \& D$ as a consequence of the lower payoff that it will receive in the event that both firms innovate. With $V_{2 \delta}^{2}>0$, the rival's reaction function shifts in the direction of greater $\mathrm{I}^{2}$, which reflects its increased incentive to invest in $R \& D$ as a consequence of the greater payoff that it will receive in the event both firms innovate.

The possibility that each reaction function may slope upward or downward generates four cases. (The stability condition requires that firm 1 have the steeper reaction function (in absolute value) in each case.) Figure 1 depicts the consequences for innovation of a reduction in exclusionary impediments to postinnovation competition for the case in which the dominant firm's reaction function is upward sloping and its rival's reaction function slopes downward. In the figure, the original reaction functions are depicted as thick solid lines; the reactions after the policy intervention are depicted as thin lines; and the equilibrium outcome shifts upward (toward higher $\mathrm{I}^{2}$ ).

As is evident from the figure, a reduction in exclusionary impediments to postinnovation competition necessarily increases rival $R \& D$ investment, and its consequences for dominant firm $\mathrm{R} \& \mathrm{D}$ investment are indeterminate. A reduction in exclusionary impediments to pre-innovation competition operates in reverse, as though reaction functions shifted from the thin lines to the thick ones in the figure. Accordingly, that policy intervention leads to a reduction in rival R\&D investment and an indeterminate change in dominant firm investment when the dominant firm's reaction function is upward sloping and the rival's reaction function slopes downward.

Table 4 summarizes what Fig. 1 and similar figures for the other three cases show about the consequences of a reduction in exclusionary impediments to preinnovation competition for each firm's equilibrium investment. In the case that is evaluated in the final column, both best response functions slope upward. Then each firm's investment level may either increase or decrease but they cannot simultaneously increase unless the policy intervention has relatively little influence on the rival's reaction function (in which case the new equilibrium would be approximately determined by shifting the dominant firm's reaction function along the rival's upward sloping reaction function).

The table indicates that a downward sloping reaction function for the dominant firm guarantees that the dominant firm will increase its investment in R\&D when exclusionary impediments to pre-innovation competition are reduced. It also shows that a downward sloping reaction function for the rival guarantees that the same policy intervention will lead the rival to reduce its investment in R\&D.

Table 5 provides a similar summary of the consequences of a reduction in exclusionary impediments to post-innovation competition. That policy intervention 


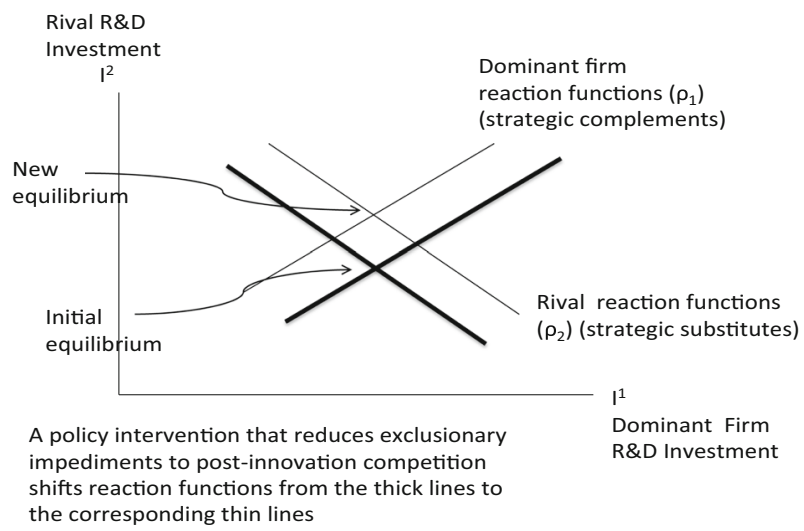

Fig. 1 Comparative statics of reducing exclusionary impediments to post-innovation competition when $\rho_{1}$ is upward sloping and $\rho_{2}$ is downward sloping

Table 4 Comparative statics of a reduction in exclusionary impediments to pre-innovation competition

\begin{tabular}{lllll}
\hline & $\mathrm{R}^{1}>0 \& \mathrm{R}^{2}<0$ & $\mathrm{R}^{1}<0 \& \mathrm{R}^{2}<0$ & $\mathrm{R}^{1}<0 \& \mathrm{R}^{2}>0$ & $\mathrm{R}^{1}>0 \& \mathrm{R}^{2}>0$ \\
\hline $\mathrm{I}^{1}$ & Indeterminate & Increases & Increases & Indeterminate \\
$\mathrm{I}^{2}$ & Decreases & Decreases & Indeterminate & Indeterminate \\
\hline
\end{tabular}

$\mathrm{R}^{1}$ is the slope of the dominant firm's reaction function $\left(\rho_{1}\right)$, and $\mathrm{R}^{2}$ is the slope of the rival's reaction function $\left(\rho_{2}\right)$

Table 5 Comparative statics of a reduction in exclusionary impediments to post-innovation competition

\begin{tabular}{lllll}
\hline & $\mathrm{R}^{1}>0 \& \mathrm{R}^{2}<0$ & $\mathrm{R}^{1}<0 \& \mathrm{R}^{2}<0$ & $\mathrm{R}^{1}<0 \& \mathrm{R}^{2}>0$ & $\mathrm{R}^{1}>0 \& \mathrm{R}^{2}>0$ \\
\hline $\mathrm{I}^{1}$ & Indeterminate & Decreases & Decreases & Indeterminate \\
$\mathrm{I}^{2}$ & Increases & Increases & Indeterminate & Indeterminate \\
\hline
\end{tabular}

$\mathrm{R}^{1}$ is the slope of the dominant firm's reaction function $\left(\rho_{1}\right)$, and $\mathrm{R}^{2}$ is the slope of the rival's reaction function $\left(\rho_{2}\right)$

shifts each reaction function in the opposite direction from a reduction in exclusionary impediments to pre-innovation competition, so it operates like a shift of the equilibrium outcome in the reverse direction from the way that the outcome moved in the cases that are described in Table 4 (as is evident, in the first column, for the case illustrated in Fig. 1). Accordingly, the sign of each determinate entry in Table 5 switches relative to the sign of the corresponding entry in Table 4.

The table indicates that a downward sloping reaction function for the rival guarantees that the rival will increase its investment in $R \& D$ when exclusionary impediments to post-innovation competition are reduced. It also shows that a downward sloping reaction function for the dominant firm guarantees that the same policy intervention will lead the dominant firm to reduce its investment in R\&D. 
Tables 4 and 5 suggest a relationship between the direction that reaction functions slope and the innovation consequences of the two competition policy interventions. To ensure conceptual clarity, the discussion will be couched in terms of the policy-maker's selecting the better intervention, ignoring the possibility that the available policy instruments could allow or would require the policy-maker to combine its interventions.

Table 4 indicates that a reduction in exclusionary impediments to pre-innovation competition stimulates dominant firm investment when the dominant firm's reaction function is downward sloping, and that rival investment cannot increase unless the rival's reaction function is upward sloping. Table 5 indicates that a reduction in exclusionary impediments to post-innovation competition stimulates rival investment when the rival's reaction function is downward sloping. It also shows that the dominant firm's R\&D investment cannot increase unless the dominant firm's reaction function is upward sloping.

The consequences of the two policy interventions for $R \& D$ investment are analyzed analytically in Propositions 3 and 4. Proposition 3 derives the consequences of a small competition policy intervention for investment by the two firms through a comparative statics analysis.

Proposition 3 (Comparative Statics) The equilibrium levels of $I^{1}$ and $I^{2}$ are increasing with marginal increases in $z$ if the following conditions hold:

$$
\begin{aligned}
d I^{1} / d z & =\left[-V_{1 z}^{1} V_{22}^{2}+V_{12}^{1} V_{2 z}^{2}\right] /\left[V_{11}^{1} V_{22}^{2}-V_{12}^{1} V_{21}^{2}\right] \\
& =\left[-V_{1 z}^{1} V_{22}^{2}+V_{12}^{1} V_{2 z}^{2}\right] / D>0 ;
\end{aligned}
$$

and

$$
\begin{aligned}
d I^{2} / d z & =\left[-V_{2 z}^{2} V_{11}^{1}+V_{21}^{2} V_{1 z}^{1}\right] /\left[V_{11}^{1} V_{22}^{2}-V_{12}^{1} V_{21}^{2}\right] \\
& =\left[-V_{2 z}^{2} V_{11}^{1}+V_{21}^{2} V_{1 z}^{1}\right] / D>0
\end{aligned}
$$

Each policy intervention could simultaneously increase both firms' R\&D investment, in which case the overall probability of innovation success necessarily rises. But in other cases, each intervention may increase one firm's R\&D investment, which boosts its probability of innovation success, while reducing the other firm's R\&D investment and thereby lessening its probability of innovation success. Proposition 4 derives the conditions under which a small policy intervention will increase the overall probability of innovation success. These propositions confirm what is evident from Tables 4 and 5: Restrictions on the signs of the slopes of the reaction functions are not sufficient to guarantee that policy interventions will benefit innovation; the steepness of those slopes and the extent to which the intervention shifts reaction functions also matter.

Proposition 4 (Conditions for Policy Interventions to Increase the Probability of Innovation) A policy intervention that raises $z$ by a small amount will increase $p$ [the probability that at least one firm succeeds] if and only if 


$$
\begin{aligned}
d p / d z= & q_{1}^{1}\left(1-q^{2}\right)\left[-V_{1 z}^{1} V_{22}^{2}+V_{12}^{1} V_{2 z}^{2}\right] / D \\
& +q_{2}^{2}\left(1-q^{1}\right)\left[-V_{2 z}^{2} V_{11}^{1}+V_{21}^{2} V_{1 z}^{1}\right] / D>0
\end{aligned}
$$

Corollary 1 A reduction in exclusionary impediments to pre-innovation competition (greater $\theta$ ) will increase $p$ if and only if

$$
\begin{aligned}
& q_{1}^{1}\left(1-q^{2}\right)\left[q_{1}^{1}\left(1-q^{2}\right) \Pi_{\theta}^{1 f f} V_{22}^{2}\right]+q_{2}^{2}\left(1-q^{1}\right)\left[\left(1-q^{1}\right) q_{2}^{2} \Pi_{\theta}^{2 f f} V_{11}^{1}\right]> \\
& \quad q_{1}^{1}\left(1-q^{2}\right)\left[\left(q_{1}^{1} q_{2}^{2} \Delta\right)\left(\left(1-q^{1}\right) q^{2} \Pi_{\theta}^{2 f f}\right)\right] \\
& \quad+q_{2}^{2}\left(1-q^{1}\right)\left[\left(q_{1}^{1} q_{2}^{2} \Psi\right)\left(q_{1}^{1}\left(1-q^{2}\right) \Pi_{\theta}^{1 f f}\right)\right] .
\end{aligned}
$$

Corollary 2 A reduction in exclusionary impediments to post-innovation competition (greater $\delta$ ) will increase $p$ if and only if

$$
\begin{array}{r}
q^{1}\left(q_{1}^{1}\right)^{2}\left(1-q^{2}\right)\left(q_{2}^{2}\right)^{2} \Pi_{\delta}^{1 s s} \Delta+\left(q_{1}^{1} q_{2}^{2}\right)^{2}\left(1-q^{1}\right) q^{2} \Pi_{\delta}^{1 s s} \Psi> \\
\left(q_{1}^{1}\right)^{2} q^{2}\left(1-q^{2}\right) \Pi_{\delta}^{1 s s} V_{22}^{2}+q_{1}^{1}\left(1-q^{1}\right)\left(q_{2}^{2}\right)^{2} \Pi_{\delta}^{1 s s} V_{11}^{1} .
\end{array}
$$

From Corollary 1, two sufficient conditions for a policy intervention that lessens exclusionary impediments to pre-innovation competition to raise the likelihood of innovation can be identified: The dominant firm's reaction function has a sufficiently downward slope ( $\Delta$ is sufficiently negative); or the rival's reaction function has a sufficiently upward slope ( $\Psi$ is sufficiently positive). (These are not necessary conditions because the left-hand side of the inequality can take on either sign.) The condition in the corollary will also be satisfied in the limit (regardless of the signs of $\Delta$ and $\Psi$ ) as $\mathrm{q}_{1}^{1}$ grows small: as the dominant firm's likelihood of innovation success becomes insensitive to its level of investment. ${ }^{13}$

Corollary 2 similarly implies two sufficient conditions for a policy intervention that lessens exclusionary impediments to post-innovation competition to raise the likelihood of innovation: The dominant firm's reaction function has a sufficiently upward slope ( $\Delta$ is sufficiently positive); or the rival's reaction function has a sufficiently downward slope ( $\Psi$ is sufficiently negative). (These are not necessary conditions because the right-hand side of the inequality can take either sign.)

The sufficient conditions for a policy intervention that reduces exclusionary impediments to pre-innovation competition to increase the likelihood of innovation (from Corollary 1 to Proposition 4) suggest that a downward sloping best-response function for the dominant firm and an upward sloping best-response function for its rival favor the success of that intervention in increasing the aggregate likelihood of

\footnotetext{
${ }^{13}$ It would also be satisfied if $V_{22}^{2}$ is sufficiently large in absolute value and $V_{11}^{1}$ is sufficiently small in absolute value; but this possibility is inconsistent with the stability condition, which will fail as $V_{11}^{1}$ approaches zero.
} 
innovation. To provide an intuition, a firm's non-strategic response to the policy intervention (its response if the other firm's investment level is held constant) will be separated from its strategic response.

A policy intervention that limits pre-innovation product market exclusion will, in the first instance (before accounting for strategic responses), encourage the dominant firm to invest more in $\mathrm{R} \& \mathrm{D}$ in order to escape competition and encourage its rival to invest less by increasing its pre-innovation profits and reducing its incentive to escape competition. The dominant firm will be encouraged to invest even more in response to the investment decision of its rival, if the dominant firm regards rival $R \& D$ as a strategic substitute. On the assumption that the dominant firm does invest more ${ }^{14}$ the rival's non-strategic incentive to cut back on R\&D will be dampened or countered if it views the dominant firm's $R \& D$ investment as a strategic complement, and amplified if it views the dominant firm's R\&D investment as a strategic substitute. If the dominant firm invests more, and its rival's R\&D investment increases or does not decline much, the aggregate probability of R\&D success may increase. In this way, the dominant firm's downward sloping reaction function and its rival's upward sloping reaction function may work together to support an increase in the overall likelihood of innovation.

For analogous reasons, the sufficient conditions for a policy intervention that reduces exclusionary impediments to post-innovation competition to increase the likelihood of innovation (from Corollary 2 to Proposition 4) suggest that an upward sloping reaction function for the dominant firm and a downward sloping best response function for the rival favor the success of that intervention. (Figure 1 depicts the case in which both occur.)

Intuitively, if we assume that the rival invests more, ${ }^{15}$ the dominant firm's nonstrategic incentive to reduce $R \& D$ will be dampened or countered if it views its own $\mathrm{R} \& \mathrm{D}$ investment as a strategic complement, and amplified if it views the rival's $\mathrm{R} \& \mathrm{D}$ investment as a strategic substitute. ${ }^{16}$ If the rival invests more, and the dominant firm's R\&D investment increases or does not decline much, the aggregate probability of R\&D success may increase.

\footnotetext{
14 Aggregate incentives to innovate may increase even if the dominant firm invests less. This outcome may arise if the rival regards the dominant firm's R\&D investment as a strong strategic complement, so long as the rival's strategic response is so substantial as to lead the rival to invest more and so long as the aggregate probability of innovation is more heavily influenced by greater rival investment than by reduced dominant firm investment. The intuition that is offered in the text emphasizes one of the sufficient conditions that are derived from Corollary 1 to Proposition 4: that the dominant firm's reaction function slopes downward. The intuition in this note emphasizes the other sufficient condition: that the rival's reaction function slopes upward.

15 Aggregate incentives to innovate may also increase even if the rival invests less. This outcome may arise if the dominant firm regards its rival's R\&D investment as a strong strategic substitute, so long as the rival's strategic response is so substantial as to lead the dominant firm to invest more and so long as the aggregate probability of innovation is more heavily influenced by greater dominant firm investment than by reduced rival investment.

${ }^{16}$ For this reason, the antitrust policy application in Baker (2016) turns on evaluating the sign of the slope of the dominant firm's reaction function.
} 


\section{Extensions}

\subsection{Payoffs that Depend on R\&D Investments}

In the model that was discussed in Sect. 2, the payoffs to successful innovation do not vary with the level of $R \& D$ investment. This assumption, which is tantamount to supposing that each firm has only one possible way to innovate, is most plausible when firms are pursuing major new products, substantial product upgrades, or drastic cost reductions. In these settings, firm payoffs to $R \& D$ investment will likely be determined primarily by whether the $R \& D$ effort succeeds.

The assumption that the payoffs to successful innovation do not vary with the level of R\&D investment is less attractive for non-drastic cost reductions. Then firm payoffs will depend in part on the way that cost reductions affect the oligopoly interaction in product markets, which is not incorporated in the model. The assumption is also less attractive in some settings that involve demand-enhancing (new product) innovation. These include the possibility that the level of investment affects the magnitude of the quality improvement (in a vertical differentiation model) or the proximity of new goods in product space (in a horizontal differentiation model). In general, when payoffs to innovation success depend on $R \& D$ investments, the slopes of reaction functions would continue to be influenced by the relative magnitude of payoffs in various states of the world, as in the model that is set forth here; but additional factors that are not incorporated in the model would also be expected to matter.

$\mathrm{R} \& \mathrm{D}$ spillovers may also lead the payoffs to innovation success to vary with the level of $R \& D$ investment. If one firm's $R \& D$ success benefits the other firm by increasing the probability that the rival would also succeed, without changing the payoffs to innovation success, the slopes of reaction functions would not change and the comparative statics results of Proposition 3 would continue to apply. ${ }^{17}$ More generally, though, positive R\&D investment spillovers would also be expected to change the payoffs to innovation success, and, in consequence, alter the way that firm $R \& D$ investments respond to reductions in exclusionary impediments to product market competition in additional ways that are not captured by the model.

On the one hand, the spillovers that are generated by a policy intervention that leads one firm to increase its $R \& D$ investment would be expected to lower the marginal cost or increase the marginal benefit of R\&D investment by its rival, which would lead the rival to increase its own $R \& D$ expenditures. On the other hand, the greater $R \& D$ investment by one firm would also increase the likelihood that its rival's $R \& D$ effort would succeed and reduce the likelihood that the rival would succeed alone. This would be expected to discourage the rival from increasing its $\mathrm{R} \& \mathrm{D}$ investment in response because it would reduce the rival's ability to escape competition by developing new products or lowering production costs, thereby

\footnotetext{
17 Even under this assumption, however, the conditions under which policy interventions increase the probability of innovation (Proposition 4) would require modification to incorporate the interdependence in probabilities of innovation success.
} 
lessening the rival's expected payoffs to innovation success. ${ }^{18}$ If positive R\&D spillovers are important, it would be necessary to account for these possible additional dynamics to determine how firms alter their R\&D investments in response to policy changes that reduce impediments to product market exclusion.

\subsection{Raising Rival R\&D Costs}

Dominant firms may also exclude innovation rivals by raising their R\&D costs, as by raising the price of inputs such as intellectual property rights. This possibility may be incorporated into the model by assuming that antitrust enforcers have a third policy instrument $(\sigma)$ that has the effect of lowering the rival's cost of R\&D investment $\mathrm{I}^{2}$. A higher $\sigma$ represents reduced exclusion, which is consistent with the way that the other policy interventions are signed.

To incorporate this possibility, the rival's $\mathrm{R} \& \mathrm{D}$ cost function is assumed to take the form $\mathrm{C}^{2}=\mathrm{C}^{2}\left(\sigma, \mathrm{I}^{2}\right)$, where $\mathrm{C}_{\sigma}^{2}<0, \mathrm{C}_{\sigma 2}^{2}<0, \mathrm{C}_{2}^{2}>0$, and $\mathrm{C}_{22}^{2}<0$. (Consistent with previous notation, the subscript 2 identifies the partial derivative with respect to $\mathrm{I}^{2}$ (which also happens to be the variable in the second position).) The assumption that $C_{\sigma 2}^{2}<0$ recognizes that a competition policy intervention that limits the ability of the dominant firm to raise its rival's R\&D costs will lower the rival's marginal cost of R\&D investment.

This modification to the model does not alter the expression for the expected value of the dominant firm $\left(\mathrm{V}^{1}\right)$, and the expected value of the rival $\left(\mathrm{V}^{2}\right)$ differs only in the form of the cost function:

$$
\begin{aligned}
\mathrm{V}^{2}= & \mathrm{q}^{2}\left(\mathrm{I}^{2}\right)\left(1-\mathrm{q}^{1}\left(\mathrm{I}^{1}\right)\right) \Pi^{2 \mathrm{fs}}+\mathrm{q}^{2}\left(\mathrm{I}^{2}\right) \mathrm{q}^{1}\left(\mathrm{I}^{1}\right) \Pi^{2 \mathrm{ss}}(\delta) \\
& +\left(1-\mathrm{q}^{2}\left(\mathrm{I}^{2}\right)\right)\left(1-\mathrm{q}^{1}\left(\mathrm{I}^{1}\right)\right) \Pi^{2 \mathrm{ff}}(\theta) \\
& +\left(1-\mathrm{q}^{2}\left(\mathrm{I}^{2}\right)\right) \mathrm{q}^{1}\left(\mathrm{I}^{1}\right) \Pi^{2 \mathrm{sf}}-\mathrm{C}^{2}\left(\sigma, \mathrm{I}^{2}\right) .
\end{aligned}
$$

Because the policy intervention parameter $\sigma$ appears only in the rival's cost function, the first-order conditions are written as before, though with the $C_{2}^{2}$ term in Eq. (2) defined differently: as a partial derivative of the cost function $\mathrm{C}\left(\sigma, \mathrm{I}^{2}\right)$ ). Comparative statics require signing the partial derivatives $\mathrm{V}_{1}^{1}$ and $\mathrm{V}_{2}^{2}$ with respect to $\sigma: \mathrm{V}_{1 \sigma}^{1}=0$, and $\mathrm{V}_{2 \sigma}^{2}=-\mathrm{C}_{\sigma 2}^{2}>0$.

Proposition 5 (Comparative Statics) The equilibrium level of $\mathrm{I}^{2}$ necessarily increases with marginal increases in $\sigma$; and the equilibrium level of $\mathrm{I}^{1}$ increases with marginal increases in $\sigma$ if and only if $\Delta>0$.

Corollary (Sufficient condition for a Policy Intervention that Reduces the Marginal Cost of Rival R\&D to Increase the Probability of Innovation) A policy intervention that raises $\sigma$ by a small amount will necessarily increase $p$ if $\Delta>0$.

\footnotetext{
18 This discussion is concerned with the way that reductions in exclusionary impediments to product market competition would alter R\&D investments by the firms, not on the way that the presence of spillovers would alter initial investment levels. Each firm's equilibrium level of R\&D investment before a policy intervention would differ from the corresponding level in a model that does not allow for R\&D spillovers because of the increased likelihood that both firms would succeed and the reduced likelihood that either firm would succeed alone.
} 
Proposition 5 and its corollary show that a competition policy intervention that reduces the marginal cost of the rival's $\mathrm{R} \& \mathrm{D}$ (greater $\sigma$ ) will necessarily increase rival investment, and will increase dominant firm investment if and only if the dominant firm regards rival investment as a strategic complement $(\Delta>0)$. In the latter case, the overall probability of innovation necessarily increases. If the dominant firm instead regards rival investment as a strategic substitute, the rival will invest more in $\mathrm{R} \& \mathrm{D}$; but the dominant firm will invest less. Under such circumstances, the effect on the overall probability of innovation success will depend on the relative magnitudes of these effects and on the way that variation in each firm's R\&D investment affects its probability of innovation success.

\section{Conclusion}

In the model of research and development competition that is set forth in this article, the innovation consequences of competition policy interventions that challenge the exclusionary conduct of dominant firms depend importantly on the direction of the strategic response of dominant firms and their rivals to each other's R\&D investments. Enforcement actions that challenge pre-innovation exclusion and enforcement actions that challenge post-innovation exclusion will tend to be effective in different strategic settings. In addition, a competition policy intervention that prevents dominant firms from excluding innovation rivals by raising their $R \& D$ costs will necessarily increase rival investment, and will increase dominant firm investment if and only if the dominant firm regards rival investment as a strategic complement. These results are relevant to the antitrust evaluation of a dominant firm's "appropriability" justification for exclusionary practices: its claim that those practices will benefit innovation by increasing its own reward for innovation success and, thus, encouraging it to invest more in R\&D (Baker 2016).

Acknowledgments The author is particularly indebted to Paolo Ramezzana. The author is also grateful to Yair Eilat, Joe Farrell, Rich Gilbert, Louis Kaplow, Steve Salop, Bobby Willig, John Woodbury, two anonymous referees, and participants in the Searle Center's Seventh Annual Conference on Antitrust Economics and Competition Policy.

Open Access This article is distributed under the terms of the Creative Commons Attribution 4.0 International License (http://creativecommons.org/licenses/by/4.0/), which permits unrestricted use, distribution, and reproduction in any medium, provided you give appropriate credit to the original author(s) and the source, provide a link to the Creative Commons license, and indicate if changes were made.

\section{Appendix}

Proposition 1 An increase in $z$ shifts $\rho_{1}$ in the direction of higher $I^{1}$ if and only if $-V_{1 z}^{1} / V_{11}^{1}>0$.

Proof Firm 1's reaction function $\mathrm{I}^{1}=\rho_{1}\left(\mathrm{I}^{2}\right)$ is defined implicitly by first order condition (1): $\mathrm{V}_{1}^{1}\left(\mathrm{I}^{1}, \mathrm{I}^{2}, \mathrm{z}\right)=0$. If we assume that $\mathrm{V}_{1}^{1}\left(\mathrm{I}^{1}, \mathrm{I}^{2}, \mathrm{z}\right)$ is continuous and differentiable, then total differentiation of Eq. (1) yields $\mathrm{V}_{11}^{1} \mathrm{dI}^{1}+\mathrm{V}_{12}^{1} \mathrm{dI}^{2}+$ 
$\mathrm{V}_{1 \mathrm{z}}^{1} \mathrm{dz}=0$. An increase in $\mathrm{z}$ shifts $\rho_{1}$ in the direction of higher $\mathrm{I}^{1}$ if and only if $\mathrm{dI}^{1} / \mathrm{dz}>0$, for $\mathrm{dI}^{2}=0$. If $\mathrm{dI}^{2}=0$, then $\mathrm{dI}^{1} / \mathrm{dz}=-\mathrm{V}_{1 \mathrm{z}}^{1} / \mathrm{V}_{11}^{1}$. Hence $\mathrm{dI} I^{1} / \mathrm{dz}>0$ if and only if $-\mathrm{V}_{1 \mathrm{z}}^{1} / \mathrm{V}_{11}^{1}$.

Proposition 2 An increase in $z$ shifts $\rho_{2}$ in the direction of higher $I^{2}$ if and only if $-V_{2 z}^{2} / V_{22}^{2}>0$.

Proof Firm 2's reaction function $\mathrm{I}^{2}=\rho_{2}\left(\mathrm{I}^{1}\right)$ is defined implicitly by first order condition (2): $\mathrm{V}_{2}^{2}\left(\mathrm{I}^{2}, \mathrm{I}^{1}, \mathrm{z}\right)=0$. If we assume that $\mathrm{V}_{2}^{2}\left(\mathrm{I}^{2}, \mathrm{I}^{1}, \mathrm{z}\right)$ is continuous and differentiable, then total differentiation of Eq. (2) yields $\mathrm{V}_{21}^{2} \mathrm{dI}^{1}+\mathrm{V}_{22}^{2} \mathrm{dI}^{2}+$ $\mathrm{V}_{2 \mathrm{z}}^{2} \mathrm{dz}=0$. An increase in $\mathrm{z}$ shifts $\rho_{2}$ in the direction of higher $\mathrm{I}^{2}$ if and only if $\mathrm{dI}^{2} / \mathrm{dz}>0$, for $\mathrm{dI}^{1}=0$. If $\mathrm{dI}^{1}=0$, then $\mathrm{dI}^{2} / \mathrm{dz}=-\mathrm{V}_{2 \mathrm{z}}^{2} / \mathrm{V}_{22}^{2}$. Hence, $\mathrm{dI}^{2} / \mathrm{dz}>0$ if and only if $-\mathrm{V}_{2 \mathrm{z}}^{2} / \mathrm{V}_{22}^{2}>0$.

Proposition 3 The equilibrium levels of $I^{1}$ and $I^{2}$ are increasing with marginal increases in $z$ if $d I^{1} / d z=\left[-V_{1 z}^{1} V_{22}^{2}+V_{12}^{1} V_{2 z}^{2}\right] /\left[V_{11}^{1} V_{22}^{2}-V_{12}^{1} V_{21}^{2}\right]=$ $\left[-V_{1 z}^{1} V_{22}^{2}+V_{12}^{1} V_{2 z}^{2}\right] / D>0$, and $d I^{2} / d z=\left[-V_{2 z}^{2} V_{11}^{1}+V_{21}^{2} V_{1 z}^{1}\right] /\left[V_{11}^{1} V_{22}^{2}-V_{12}^{1} V_{21}^{2}\right]=$ $\left[-V_{2 z}^{2} V_{11}^{1}+V_{21}^{2} V_{1 z}^{1}\right] / D>0$.

Proof The equilibrium levels of $\mathrm{I}^{1}$ and $\mathrm{I}^{2}$ are increasing with marginal increases in $\mathrm{z}$ if $\mathrm{dI}^{1} / \mathrm{dz}>0$ and $\mathrm{dI}^{2} / \mathrm{dz}>0$, respectively. The equilibrium levels of $\mathrm{I}^{1}$ and $\mathrm{I}^{2}$ are defined by the simultaneous solution of the first-order conditions (1) and (2), on the assumption that the second-order conditions hold. As indicated in the proofs of Propositions 1 and 2, total differentiation of these conditions yields $\mathrm{V}_{11}^{1} \mathrm{dI}^{1}+\mathrm{V}_{12}^{1} \mathrm{dI}^{2}+\mathrm{V}_{1 \mathrm{z}}^{1} \mathrm{dz}=0$ and $\mathrm{V}_{21}^{2} \mathrm{dI}+\mathrm{V}_{22}^{2} \mathrm{dI}^{2}+\mathrm{V}_{2 \mathrm{z}}^{2} \mathrm{dz}=0$. The simultaneous solution of these equations implies $\mathrm{dI} / \mathrm{dz}=\left[-\mathrm{V}_{1 \mathrm{z}}^{1} \mathrm{~V}_{22}^{2}+\mathrm{V}_{12}^{1} \mathrm{~V}_{2 \mathrm{z}}^{2}\right] / \mathrm{D}$ and $\mathrm{dI}^{2} / \mathrm{dz}=\left[-\mathrm{V}_{2 \mathrm{z}}^{2} \mathrm{~V}_{11}^{1}+\mathrm{V}_{21}^{2} \mathrm{~V}_{1 \mathrm{z}}^{1}\right] / \mathrm{D}$, where, by definition, $\mathrm{D}=\left[\mathrm{V}_{11}^{1} \mathrm{~V}_{22}^{2}-\mathrm{V}_{12}^{1} \mathrm{~V}_{21}^{2}\right]$.

Proposition 4 A policy intervention that raises $z$ by a small amount will increase $p$ if and only if $d p / d z=q_{1}^{1}\left(1-q^{2}\right)\left[-V_{1 z}^{1} V_{22}^{2}+V_{12}^{1} V_{2 z}^{2}\right] / D+$ $q_{2}^{2}\left(1-q^{l}\right)\left[-V_{2 z}^{2} V_{11}^{l}+V_{21}^{2} V_{1 z}^{l}\right] / D>0$.

Proof By definition, $\mathrm{p}(\mathrm{z})=\mathrm{q}^{1}\left(\mathrm{I}^{1}\right)+\mathrm{q}^{2}\left(\mathrm{I}^{2}\right)-\mathrm{q}^{1}\left(\mathrm{I}^{1}\right) \mathrm{q}^{2}\left(\mathrm{I}^{2}\right)$, with $\mathrm{I}^{1}(\mathrm{z})$ and $\mathrm{I}^{2}(\mathrm{z})$. Differentiating with respect to $z$ yields dp/dz $=q_{1}^{1}\left(1-q^{2}\right) \mathrm{dI}^{1} / \mathrm{dz}+\mathrm{q}_{2}^{2}\left(1-\mathrm{q}^{1}\right)$ $\mathrm{dI}^{2} / \mathrm{dz}$. By Proposition 3, $\mathrm{dI}^{1} / \mathrm{dz}=\left[-\mathrm{V}_{1 \mathrm{z}}^{1} \mathrm{~V}_{22}^{2}+\mathrm{V}_{12}^{1} \mathrm{~V}_{2 \mathrm{z}}^{2}\right] / \mathrm{D}$ and $\mathrm{dI}^{2} / \mathrm{dz}=$ $\left[-\mathrm{V}_{2 \mathrm{z}}^{2} \mathrm{~V}_{11}^{1}+\mathrm{V}_{21}^{2} \mathrm{~V}_{1 \mathrm{z}}^{1}\right] / \mathrm{D}$. Hence $\mathrm{dp} / \mathrm{dz}=\mathrm{q}_{1}^{1}\left(1-\mathrm{q}^{2}\right)\left[-\mathrm{V}_{1 \mathrm{z}}^{1} \mathrm{~V}_{22}^{2}+\mathrm{V}_{12}^{1} \mathrm{~V}_{2 \mathrm{z}}^{2}\right] / \mathrm{D}+$ $\mathrm{q}_{2}^{2}\left(1-\mathrm{q}^{1}\right)\left[-\mathrm{V}_{2 \mathrm{z}}^{2} \mathrm{~V}_{11}^{1}+\mathrm{V}_{21}^{2} \mathrm{~V}_{1 \mathrm{z}}^{1}\right] / \mathrm{D}$.

Proposition 5 The equilibrium level of $I^{2}$ necessarily increases with marginal increases in $\sigma$, and the equilibrium level of $I^{1}$ increases with marginal increases in $\sigma$ if and only if $\Delta>0$.

Proof The equilibrium levels of $\mathrm{I}^{1}$ and $\mathrm{I}^{2}$ are increasing with marginal increases in $\sigma$ if and only if $\mathrm{dI}^{1} / \mathrm{d} \sigma>0$ and $\mathrm{dI}^{2} / \mathrm{d} \sigma>0$, respectively. In this problem, the objective functions of the two firms are written $\mathrm{V}^{1}=\mathrm{q}^{1}\left(\mathrm{I}^{1}\right)\left(1-\mathrm{q}^{2}\left(\mathrm{I}^{2}\right)\right) \Pi^{1 \text { sf }}+$ $\mathrm{q}^{1}\left(\mathrm{I}^{1}\right) \mathrm{q}^{2}\left(\mathrm{I}^{2}\right) \Pi^{1 \mathrm{ss}}(\delta)+\left(1-\mathrm{q}^{1}\left(\mathrm{I}^{1}\right)\right)\left(1-\mathrm{q}^{2}\left(\mathrm{I}^{2}\right)\right) \Pi^{1 \mathrm{ff}}(\theta)+\left(1-\mathrm{q}^{1}(\mathrm{I})\right) \mathrm{q}^{2}\left(\mathrm{I}^{2}\right) \Pi^{1 \mathrm{fs}}-\mathrm{C}^{1}\left(\mathrm{I}^{1}\right)$, and $\mathrm{V}^{2}=\mathrm{q}^{2}\left(\mathrm{I}^{2}\right)\left(1-\mathrm{q}^{1}\left(\mathrm{I}^{1}\right)\right) \Pi^{2 \mathrm{fs}}+\mathrm{q}^{2}\left(\mathrm{I}^{2}\right) \mathrm{q}^{1}\left(\mathrm{I}^{1}\right) \Pi^{2 \mathrm{ss}}(\delta)+\left(1-\mathrm{q}^{2}\left(\mathrm{I}^{2}\right)\right)\left(1-\mathrm{q}^{1}\left(\mathrm{I}^{1}\right)\right) \Pi^{2 \mathrm{ff}}(\theta)+$ $\left(1-\mathrm{q}^{2}\left(\mathrm{I}^{2}\right)\right) \mathrm{q}^{1}\left(\mathrm{I}^{1}\right) \Pi^{2 \mathrm{sf}}-\mathrm{C}^{2}\left(\sigma, \mathrm{I}^{2}\right)$. The first order conditions that are solved 
simultaneously for $\mathrm{I}^{1}(\sigma)$ and $\mathrm{I}^{2}(\sigma)$ require $\mathrm{V}_{1}^{1}=0=\mathrm{q}_{1}^{1}\left(1-\mathrm{q}^{2}\right) \Pi^{1 \mathrm{sf}}+$ $\mathrm{q}_{1}^{1} \mathrm{q}^{2} \Pi^{1 \mathrm{ss}}-\mathrm{q}_{2}^{1}\left(1-\mathrm{q}^{2}\right) \Pi^{1 \mathrm{ff}}-\mathrm{q}_{1}^{1} \mathrm{q}^{2} \Pi^{1 \mathrm{fs}}-\mathrm{C}_{1}^{1}$, and $\mathrm{V}_{2}^{2}=0=\mathrm{q}_{2}^{2}\left(1-\mathrm{q}^{1}\right) \Pi^{2 \mathrm{fs}}+$ $q_{2}^{2} q^{1} \Pi^{2 s s}-q_{2}^{2}\left(1-q^{1}\right) \Pi^{2 f f}-q_{2}^{2} q^{1} \Pi^{2 s f}-C_{2}^{2}$. Total differentiation of the first order conditions implies $\mathrm{V}_{11}^{1} \mathrm{dI}^{1}+\mathrm{V}_{12}^{1} \mathrm{dI}^{2}+\mathrm{V}_{1 \sigma}^{1} \mathrm{~d} \sigma=0$ and $\mathrm{V}_{21}^{2} \mathrm{dI}^{1}+\mathrm{V}_{22}^{2} \mathrm{dI}^{2}+$ $\mathrm{V}_{2 \sigma}^{2} \mathrm{~d} \sigma=0$, which imply in turn that $\mathrm{dI}^{1} / \mathrm{d} \sigma=\left[\mathrm{V}_{12}^{1} \mathrm{~V}_{2 \sigma}^{2}\right] / \mathrm{D}$ and $\mathrm{dI}^{2} / \mathrm{d} \sigma=$ $\left[-\mathrm{V}_{2 \sigma}^{2} \mathrm{~V}_{11}^{1}\right] / \mathrm{D}$, where, by definition, $\mathrm{D}=\left[\mathrm{V}_{11}^{1} \mathrm{~V}_{22}^{2}-\mathrm{V}_{12}^{1} \mathrm{~V}_{21}^{2}\right]$. The expression $\mathrm{dI}^{2} / \mathrm{d} \sigma$ is necessarily positive because $\mathrm{V}_{2 \sigma}^{2}=-\mathrm{C}_{\sigma 2}>0, \mathrm{~V}_{11}^{1}<0$, and $\mathrm{D}>0$. (If the reaction functions have opposite signs, $\mathrm{D}$ is necessarily positive. If the reaction functions have the same sign, $\mathrm{D}$ is positive by virtue of the assumption that the equilibrium is stable.) In the expression for $\mathrm{dI}^{1} / \mathrm{d} \sigma, \mathrm{V}_{\sigma 2}^{2}>0$ and $\mathrm{D}>0$, so $\mathrm{dI}^{1} / \mathrm{d} \sigma$ has the same sign as $\mathrm{V}_{12}^{1}$, which has the sign of $\Delta$.

\section{References}

Aghion, P., Bechtold, S., Cassar, L., \& Herz, H. (2014). The causal effects of competition on innovation: Experimental evidence. NBER working paper no. 19987. Retrieved 31 Aug 2015, from the NBER Web site: http://www.nber.org/papers/w19987.pdf.

Aoki, R., \& Spiegel, Y. (2010). Pre-grant patent publication and cumulative innovation. International Journal of Industrial Organization, 27, 333-345.

Athey, S., \& Schmutzler, A. (2011). Investment and market dominance. RAND Journal of Economics, 32, $1-26$.

Baker, J. B. (2007). Beyond Schumpeter vs. Arrow: How antitrust fosters innovation. Antitrust Law Journal, 74, 575-602.

Baker, J. B. (2013). Exclusion as a core competition concern. Antitrust Law Journal, 78, 527-589.

Baker, J. B. (2016). Evaluating appropriability defenses for the exclusionary conduct of dominant firms in innovative industries. Antitrust Law Journal. Working paper retrieved 31 Aug 2015, from the SSRN Web site: http://ssrn.com/abstract=2523203.

Gilbert, R. (2006). Looking for Mr. Schumpeter: Where are we in the competition-innovation debate? In A. Jaffe, J. Lerner, \& S. Stern (Eds.), Innovation policy and the economy (Vol. 6, pp. 159-215). Cambridge, Mass. and London: The MIT Press.

Gomellini, M. (2013). Innovation and competition: A survey. Working paper (Dec.). Retrieved 31 Aug 2015 from the Banca d'Italia Web site: http://www.bancaditalia.it/pubblicazioni/altri-atti-convegni/ 2014-innovazione-italia/Gomellini.pdf.

Schmutzler, A. (2010). Is competition good for innovation? A simple approach to an unresolved question. Foundations and Trends in Microeconomics, 5, 355-428.

Schmutzler, A. (2013). Competition and investment-A unified approach. International Journal of Industrial Organization, 31, 477-487.

Segal, I., \& Whinston, M. (2007). Antitrust in innovative industries. American Economic Review, 97, $1703-1730$

Shapiro, C. (2012). Competition and innovation: Did Arrow hit the bull's eye? In J. Lerner \& S. Stern (Eds.), The rate and direction of inventive activity revisited (pp. 361-410). Chicago and London: University of Chicago Press.

Tombak, M. (2006). Strategic asymmetry. Journal of Economic Behavior \& Organization, 61, 339-350.

Vives, X. (1999). Oligopoly pricing: Old ideas and new tools. Cambridge, Mass. and London: The MIT Press.

Vives, X. (2005). Complementarities and games: New developments. Journal of Economic Literature, 43, $437-479$.

Vives, X. (2008). Innovation and competitive pressure. Journal of Industrial Economics, 56, 419-469. 